\title{
IS THERE A HOLE IN THE OZONE LAYER OF YOUR CLIMATE CHANGE?

\author{
FROM SCIENTIFIC CULTURE TO POPULAR CULTURE
}

\author{
Pablo Ángel Meira Cartea
}

Eight out of ten Spaniards think the hole in the ozone layer, caused by human actions, is the key physical cause of climate change. This belief, constructed from scientific elements (concepts, images, icons, discourse), is a product of popular culture. Science has never confirmed this relationship. It was the ability of popular culture to incorporate scientific "objects" according to its own epistemology that established and popularised the idea until it became a global cultural belief. The divergence between social and scientific representation invites us to reflect upon how contemporary societies embrace and remodel scientific culture to construct representations for interpreting reality and directing responses (or inaction) to threats identified by science.

Keywords: scientific culture, popular culture, social representation, climate change, ozone.

Dear reader, if I could place a bet that your answer to the question posed by the title of this article is «yes», I would. Considering the readership profile of this journal, the odds that I will win the bet are reduced, but they are still sufficiently high for me to take my chances. For example, I presume, that the majority of MÈTODE`s readers are scientifically literate. However, it is probable that the ozone layer plays an important role in many people's mental representation of climate change.

In other words, their comprehension of climate change science, has led to the perception that «the hole in the ozone layer» is probably the atmospheric disruption responsible for the increase in global temperature and the trigger of global climatic changes, whose social and biophysical implications institutions such as the IPCC (Intergovernmental Panel on Climate Change) have warned us about.

The typical version of this belief can be outlined as follows: human activity has been releasing a number of gases into the atmosphere, including carbon dioxide $\left(\mathrm{CO}_{2}\right)$, which is the most significant, and

chlorofluorocarbons (CFCs) in increasing amounts since the beginning of the Industrial Revolution.

In some way, this pollution degrades the ozone layer creating a «hole» through which solar radiation can penetrate further, heating the atmosphere and disrupting the climate. This simplified version, which attributes climate destabilisation to the hole in the ozone layer, adopts many forms in popular culture. In some versions, causation is even reversed and climate change becomes the cause of the hole in the ozone layer.

\author{
"A BELIEF ATTRIBUTING \\ CLIMATE DESTABILISATION \\ TO THE HOLE IN THE OZONE \\ LAYER, ADOPTS MANY FORMS \\ IN POPULAR CULTURE»
}

\section{AN UNSCIENTIFIC RELATIONSHIP}

Why would I bet on your affirmative answer to the question in the title? Because I have an insider's knowledge. Since social science started analysing how climate change became a significant problem for human societies (and, therefore, an «object» of popular culture), different investigations have revealed the emergence and spread of this belief. Although climate change science has never established a causal link between climate change and the depletion of the ozone layer, the way they 
have been merged in the public arena and how they took root in popular culture, has led to a social representation in which they are closely linked.

If you share this belief, either the basic version or one of its variants, you should be aware that this connection was never confirmed by science. The relationship between the two phenomena is tangential. Obviously, both are the result of the negative impact of human activity on the delicate physical and chemical balance that makes the troposphere habitable. CFCs, the synthetic gases responsible for the deterioration of the ozone layer in the higher layers of the atmosphere, are also greenhouse gases, but their contribution to global warming is very limited compared to that of $\mathrm{CO}_{2}$ or methane. In fact, the gases that have replaced CFCs under the implementation of the Montreal Protocol (1987) to stop the deterioration of the ozone layer are also greenhouse gases.

Other connections are more complex and have not yet been sufficiently studied. For instance, the scientific community has evidence that the warming of the troposphere causes the stratosphere to cool: heat remains in the troposphere due to greenhouse gases and can no longer reach the higher layers of the atmosphere, where the thin layer of ozone protects us from UV radiation. The resulting cooling of the stratosphere can affect ozone chemistry and slow down the recovery of this layer, which is essential for life. If this were a crime novel, the hole in the ozone layer would be the perfect false suspect.

In addition, the belief that ozone depletion is part of the physicochemical mechanism that increases the temperature of the Earth is universal. Comparative social research detects it in every society studied; especially in the most advanced ones, but also in emerging countries in Asia and Latin America (Capstick, Whitmarsh, Poortinga, Pidgeon, \& Upham, 2014; Leiserowitz, 2006). Furthermore, it is a crosssectional belief, shared by many different population groups within a society, with varying levels of access to scientific culture.

Using a significant analogy, we could say that this «great misunderstanding» is a cultural pandemic: a scientifically baseless belief, the product of popular culture's creativity; an idea that managed to «infect» the mental representation of climate change for millions of people. This epidemic potential leads us to consider its social and cultural nature: is it a mental representation turned into a public representation, or a public representation turned into a mental representation? As stated by Sperber (2005, p. 11), «culture is made, first and foremost, of such

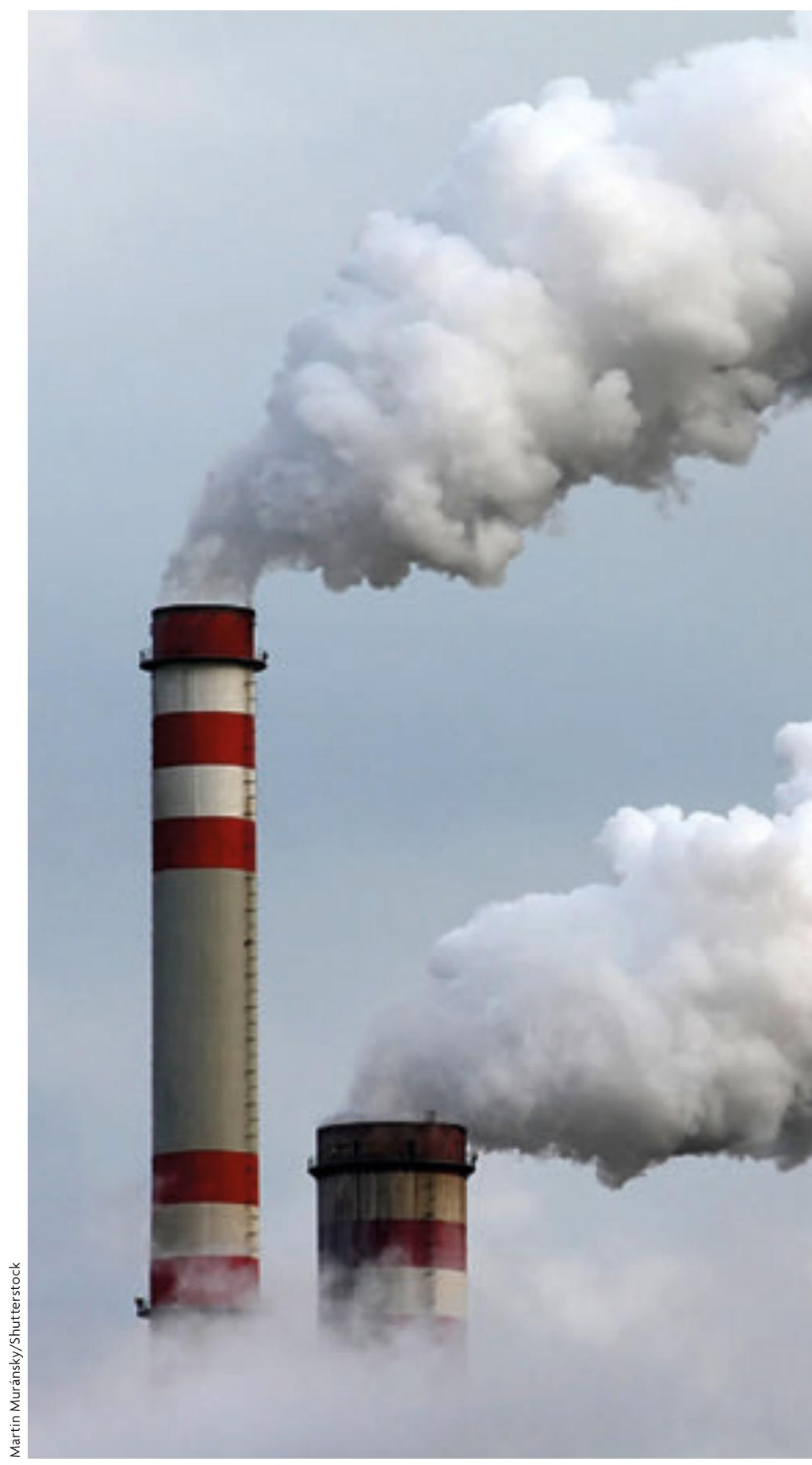

There is the belief in popular culture that climate change is a consequence of the hole in the ozone layer. According to the general representation, pollution from gases produced by human activity is poured into the atmosphere, which depletes the ozone layer. Depletion produces a «hole» through which the sun's radiation enters the atmosphere more intensively, heats it and causes climate change. But even if the depletion of the ozone layer and climate change are consequences of the impact of human activity on Earth, there is no cause/consequence connection between both phenomena. 


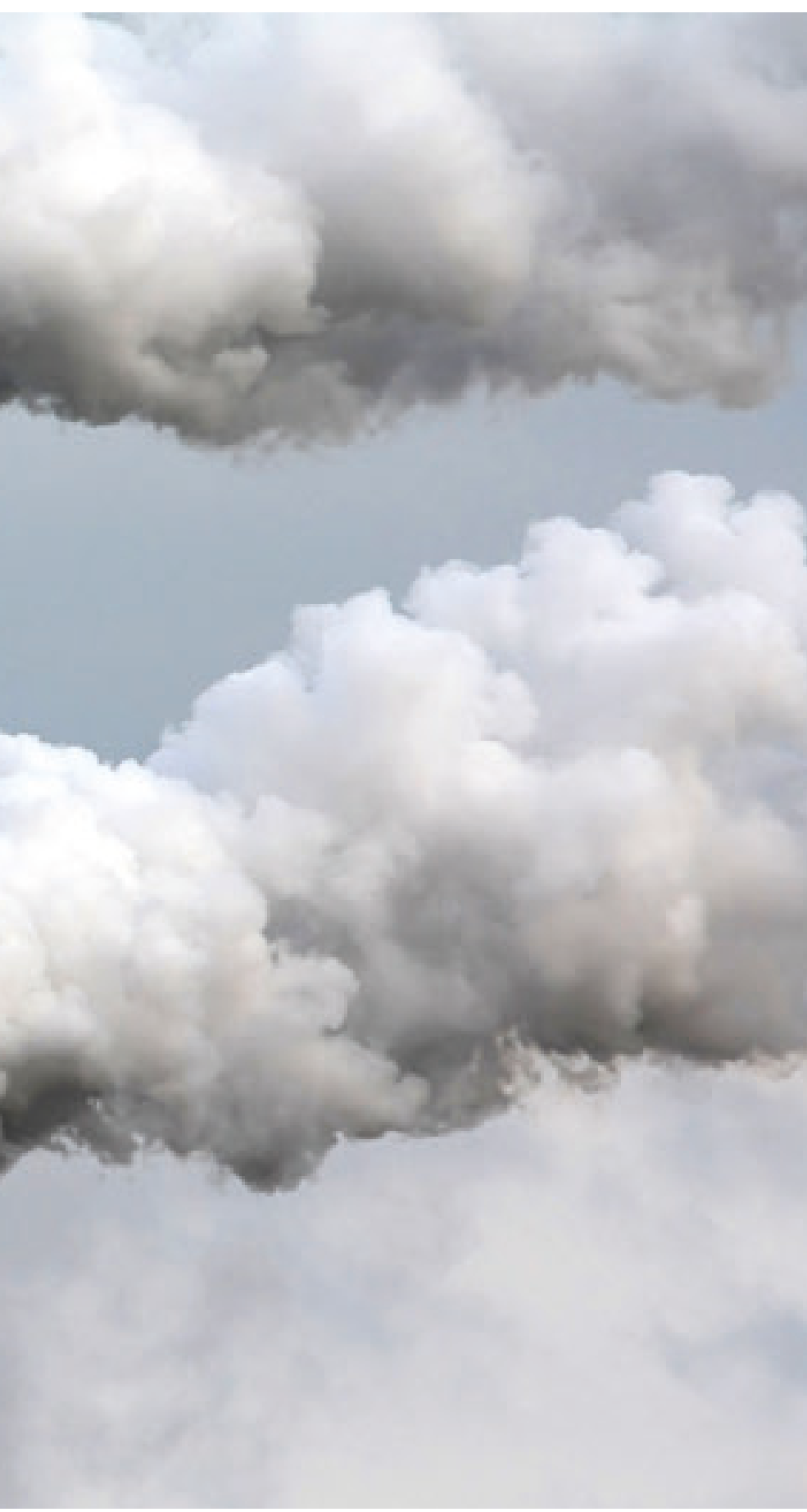

"CFCS ARE ALSO GREENHOUSE GASES, BUT THEIR CONTRIBUTION TO GLOBAL WARMING IS VERY LIMITED COMPARED TO THAT OF CARBON DIOXIDE» contagious ideas [...] To explain culture, then, is to explain how and why some ideas are contagious. This calls for a true epidemiology of representations.»

\section{PERCEPTION IN SPANISH SOCIETY}

Spanish society is not immune to this cultural pandemic. According to data from a number of studies on representative samples of the Spanish population (see Figure 1), the percentage of those who agree with the statement «climate change is a consequence of the hole in the ozone layer» has increased progressively, from 59\% in 2000 according to CIS (Centre for Sociological Investigation), which conducted the first Spanish study on the subject, to $71.1 \%$ in 2013 (Meira, Arto, \& Montero, 2009; Meira, Arto, Montero, \& Heras, 2011; Meira et al., 2013). ${ }^{1}$ The fact that 7 out of every 10 people accept this belief provides a good basis for a positive answer to my initial question. What seems extraordinary, from a cultural point of view, is that the belief has continued to gain popularity despite the fact that climate change science has greatly contributed to understanding the phenomenon, the role played by human action in its genesis and the potential threat it poses.

Brechin (2010) suggested, in a cross-cultural analysis of this kind of study that the popular link between ozone and climate change has tended to subside in recent years. We argue that this is not the case, at least not in Spanish society. What may be happening is that the scientific and social interest in climate change has moved from the cognitive dimension, concerned with knowledge and the comprehension of the issue, to other dimensions identified as more important in activating a public response to climate threat: relevance, the perception of vulnerability, values and emotions, the role of the media and media figures, the positioning of climate change on the public agenda, etc.

Beyond this belief's, apparently, minor importance in inhibiting or motivating a conclusive response to climate change, the «great misunderstanding» offers a great opportunity to investigate the relationship established between science and popular or lay culture. Climate change is a scientific object, an abstraction - just as climate is - created by both physics and natural sciences to account for a hyper-complex phenomenon with an enormous significance for humans due to its

${ }_{1}^{1}$ Public opinion studies made by the Mapfre Foundation, from which these results were drawn, followed the same design. For the latest study (Meira et al., 2013), specifications were as follows: door-to-door interviews with a representative sample of Spanish population aged 18 and older $(n=1,300)$. Confidence level of $95 \%$ for $\mathrm{p}=\mathrm{q}=0.5$. Sample error $\pm 2.7 \%$. 


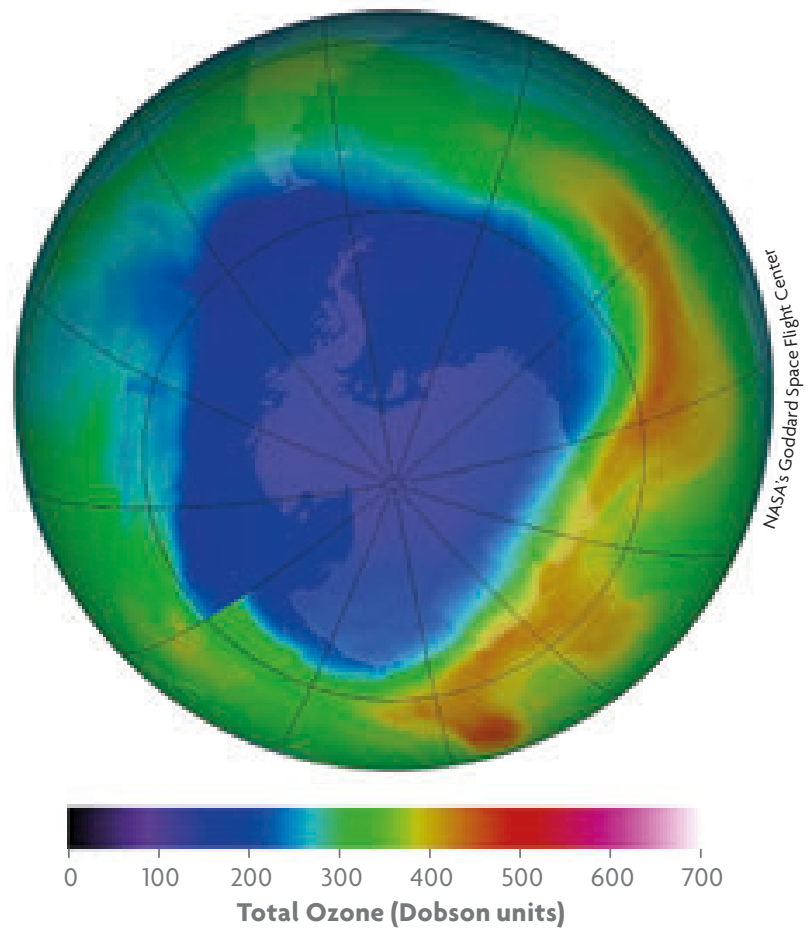

Ozone concentrations over the South Pole on 16 September 2013, collected by NASA's OMI (Ozone Monitoring Instrument). This graphic representing the ozone hole as a dark spot over Antarctica occupies a central place in contemporary iconography. Despite the fact that it is an infographic representation of numerical data, for many people this image of the ozone hole is «real».

implications. Moscovici (1961-1979) warned in the 1960s that, in contemporary cultures, scientific «objects» would play an increasingly crucial role in social life, colonising the cultural tools we use to interpret the world and guiding our individual and collective action. The theory of social representations emerges as an epistemology of popular culture, to try to understand how that culture appropriates scientific objects, such as climate change, and recreates them; to understand, in short, how a scientific representation transforms into a social representation and what implications this alchemy has for public life and to understand the connections between science and society.

\section{FROM THE OZONE HOLE TO CLIMATE CHANGE}

What turned the hole in the ozone layer into a central element in the social representation of climate change? This is not easy to answer in a few lines. In this transposition, there is interaction between individual cognitive processes, linked to how we capture new information and integrate it into what we already know, and contextual processes, related to timing, to the role of mediating institutions (media, educational system,

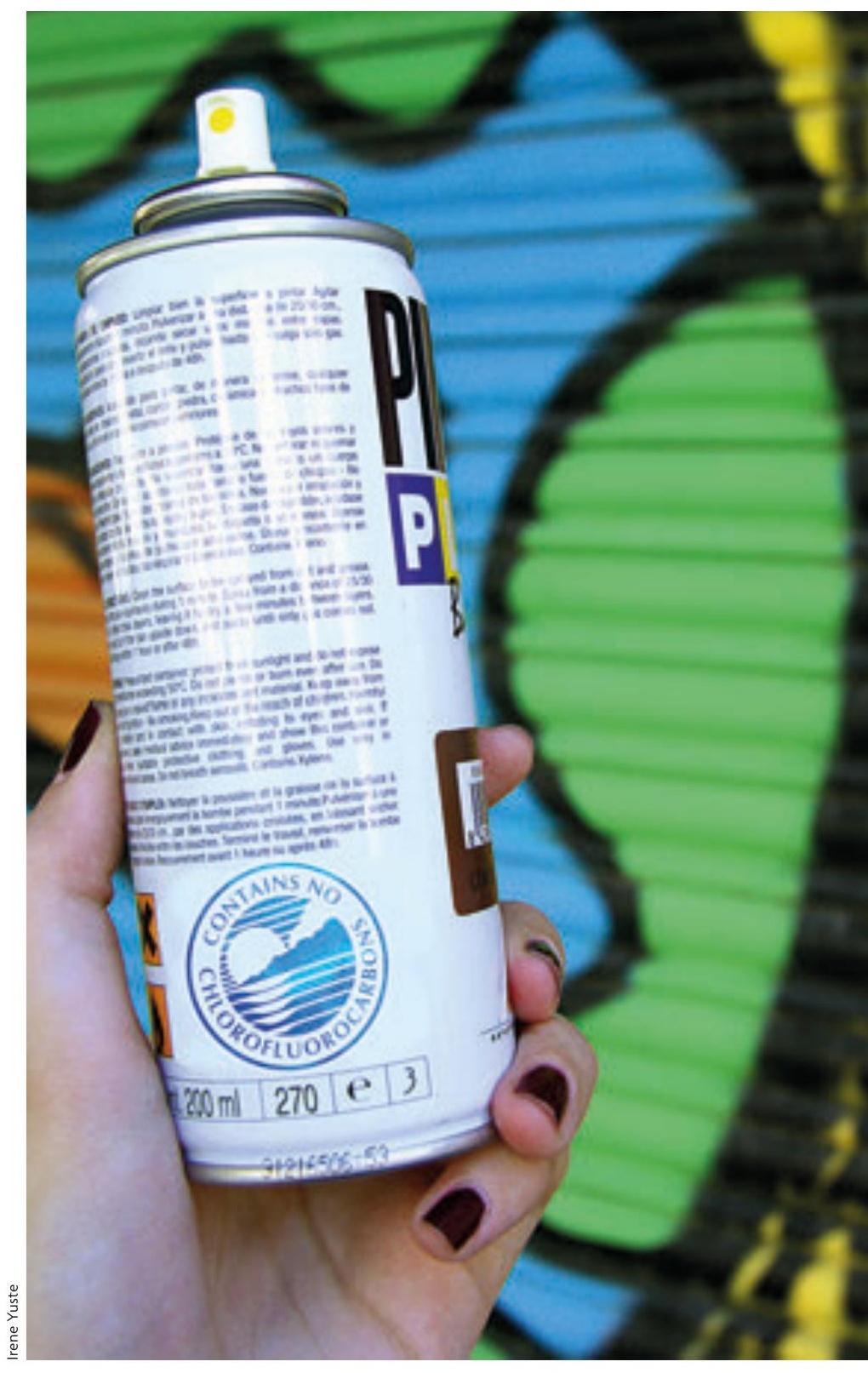

Chlorofluorocarbons, or CFCs, replaced with other gases after the Montreal Protocol in 1987, are the synthetic gases responsible for the damage to the ozone layer. However, both CFCs and their replacements are greenhouse gases, although their contribution is quite modest compared that of to carbon dioxide $\left(\mathrm{CO}_{2}\right)$.

\author{
"THE IDENTIFICATION OF AEROSOL \\ SPRAYS AS THE CAUSE FOR CFC \\ POLLUTION LINKED A COMMON,
} EVERYDAY ITEM WITH A GLOBAL THREAT, TRANSFERRING THE PROBLEM TO THE PERSONAL SPHERE» 
political institutions, etc.) and to the social interactions in which we negotiate and share our representations of the world with others. Social research provides some clues about these issues. Here, due to space limitations, we will only discuss one of them in detail.

Ozone depletion reached social relevance a decade before climate change did. The depletion of atmospheric ozone jumped from the field of science to the public sphere in the mid 1970s. Oreskes and Conway (2010) meticulously reconstruct that moment, starting with the social impact of the first studies by Crutzen, Rowland and Molina in the seventies about the role CFCs play in the depletion of stratospheric ozone, which won them a Nobel Prize for Chemistry in 1995.

In a short time, the destruction of the ozone layer became what Ungar (2000) calls a «hot crisis»: a crucial issue that focused public attention, turned into a significant global threat and generated a trend of opinion that led to the political consensus that made the Montreal Protocol possible (1987). This process, taking two decades from the construction of the scientific object to its social appropriation,

«IN SPAIN, THE PERCENTAGE OF PEOPLE WHO AGREE WITH THE STATEMENT "CLIMATE CHANGE IS A CONSEQUENCE OF THE HOLE IN THE OZONE LAYER" HAS INCREASED FROM 59\% IN 2000 TO $71.1 \%$ IN 2013"

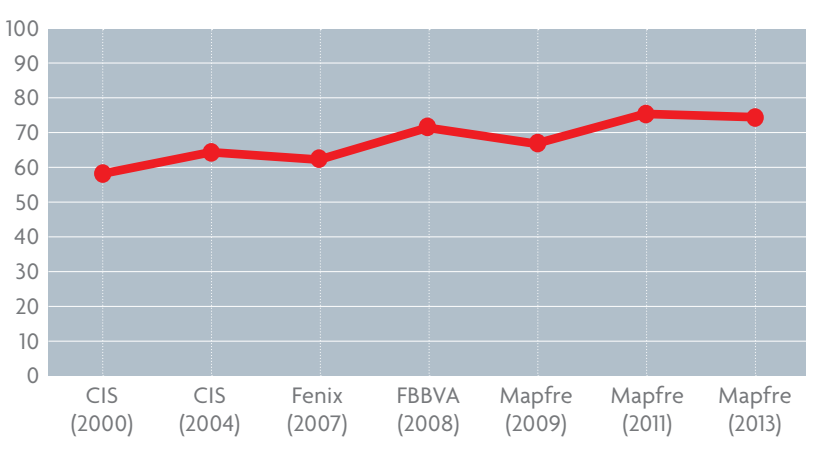

Fire 1. Evolution of the percentage of Spanish population who think the statement "Climate change is a consequence of the hole in the ozone layer" is "completely" or "probably true". was no bed of roses where

(scientific) reason simply prevailed.

In fact, Oreskes and Conway (2010, pp. 107-135) relate

how the ozone issue was used by neo-conservative lobbies with ties to the chemical industry producing CFCs to test the strategies of public communication and manipulation that they now use to question the science of climate change.

Ungar $(2000,2007)$ sets out two key points to explain the social success of the ozone problem. The first is the construction of a powerful visual metaphor, «the ozone hole», which objectified it for society. The image of a huge blue, almost black, spot darkening the South Pole still occupies a central place in contemporary iconography. Who would not remember the threat of the ozone hole upon seeing it? Qualitative studies on the iconography of ozone and climate change show that, for many people, that image is «real», when what we actually see is an infographic made using numerical data (Arto, 2010; Meira, 2006). There is no such hole in the ozone layer, or at least not in the way society has crystallised it. The second key to transforming ozone into a «hot crisis» was its association with skin cancer, a disturbing, personal, direct and significant consequence that fits perfectly with the metaphor of the «hole» through which solar radiation mercilessly «penetrates».
In our opinion, there are two other reasons that help us understand how ozone depletion became a socially significant problem. The first reason was the possibly unintentional success in the communication strategy of the environmental movement: identifying aerosol sprays as «causes» of CFC pollution. Although not one of the main industrial uses of CFCs, it linked a common, everyday item with a global threat, transferring the problem to the personal sphere. Aerosol sprays had yet another advantage: identified as CFC sources, doing without them did not involve any substantial change in people's lifestyle. As we are aware, companies quickly changed the presentation of their products to different formats that consumers would not associate with the ozone layer.

The second reason was that CFC production was relatively recent (it started in the 1940s) and was concentrated in a few industries. The initial impulse of these companies to question ozone depletion and the role of CFCs in the process, as stated by Oreskes and Conway (2010), soon declined due to the social alarm generated and a more realistic analysis of the impact possible solutions would have on their interests: replacing CFCs with ozone-friendly substances was not revolutionary for production; in fact, some already existed and, in any case, the same chemical industries profited from the development of alternative compounds.

\section{THE SOCIAL REPRESENTATION OF CLIMATE CHANGE}

What is the relevance of the timing of the ozone crisis for our subject matter? Well, climate change came 
afterwards. It debuted in the nineties, when we still looked askance at that «hole» that left us at the mercy of solar radiation. The theory of social representations warns us that, when faced with a new «object», cognitive economy leads us to reuse elements from previous representations to create the new one. For better or for worse, people cannot devote a lot of time to construct and validate the scientific basis for their understanding of reality, even people who would be considered scientifically literate.

Under these circumstances, cognitive economy and social negotiation of meaning operate at full capacity. The ozone hole was there, in the inventory of popular culture: it referred to an atmospheric problem derived from human interference, we talk about CFCs as greenhouse gases, we see solar radiation entering the atmosphere and reaching us; why not resort to using it to explain climate change?

The success of this mental representation in some minds was enough for the processes of social interaction conversations, media, social networks, etc. - to act as vectors of infection for the belief. Its prevalence explains, for instance, that much of the Spanish population still considers cancer to be the main health threat resulting from climate change. The connection does not exist, except in its link to the ozone layer (Meira et al., 2013).

The social representation of climate change, for better or for worse - we cannot be sure -, was built on the social representation of ozone layer depletion. Physical and natural sciences play an increasingly important role in the way we understand and act, individually and collectively, regarding the impacts of human systems on the delicate balance of the biosphere. But this science is inevitably processed, reconstructed and integrated in popular culture, serving as raw material for social representations, which are, ultimately, fundamental to understanding the nature of the threats we face and the way we respond to them. In fact, our future may depend on the way social, personal and collective practices arise from this representation. Exploring epistemology and, in Sperber's words (2005), the epidemiology of representations that feed popular culture - might help to improve scientific education and communication efforts associated with climate change and other similar «objects».
I do not know whether this knowledge, although partial, won me the bet, I hope it did. You can let us know. In any case, do not forget, if it was there, to remove the hole in the ozone layer from your representation of climate change. This will improve your understanding of the problem, and hopefully your willingness to consider it relevant, and act accordingly in your private life and in the public sphere. Thank you.

«THE OZONE ISSUE WAS
USED BY NEO-CONSERVATIVE
LOBBIES TO TEST THE
STRATEGIES OF PUBLIC
COMMUNICATION AND
MANIPULATION STRATEGIES
THAT THEY NOW USE TO
QUESTION THE SCIENCE OF
CLIMATE CHANGE»

REFERENCES

Arto, M. (2010). El cambio climático narrado por alumnos de educación primaria y secundaria: Propuesta de análisis para dibujos y textos. In M. Junyent, \& L. Cano (Coord.), Investigar para avanzar en educación ambiental. Madrid: Ministerio de Medio Ambiente, Medio Rural y Marino. Brechin, S. R. (2010). Public opinion: A cross-national view. In C. Lever-Tracy (Ed.), Routledge International Handbook of Climate Change and Society. New York: Routledge Press.

Capstick, S., Whitmarsh, L., Poortinga,

W., Pidgeon, N., \& Upham, P. (2014). International trends in public perceptions of climate change over the past quarter century. WIREs Climate Change. doi: 10.1002/ wcc. 321

Leiserowitz, A. A. (2006). American risk perceptions: Is climate change dangerous? Risk Analysis, 5-6, 1433-1442. Meira, P. A. (2006). Las ideas de la gente sobre el cambio climático. Ciclos: Cuadernos de Comunicación, Educación e Interpretación Ambiental, 18, $5-12$.

Meira, P. A., Arto, M., \& Montero, P. (2009). La sociedad ante el cambio climático. Conocimientos, valoraciones y comportamientos en la sociedad española. Madrid: Fundación Mapfre.

Meira, P. A., Arto, M., Montero, P., \& Heras, F. (2011). La sociedad ante el cambio climático. Conocimientos, valoraciones y comportamientos en la sociedad española. Madrid: Fundación Mapfre.

Meira, P. A., Arto, M., Heras, F., Iglesias, L., Lorenzo, J. J., \& Montero, P. (2013). La respuesta de la sociedad española ante el cambio climático. 2013. Madrid: Fundación Mapfre.

Moscovici, S. (1979). El psicoanálisis, su imagen y su público. Buenos Aires: Huemul. (Original published in 1961).

Oreskes, N., \& Conway, E. M. (2010). Merchants of doubt. How a handful of scientists obscured the truth on issues from tobacco smoke to global warming. New York: Bloomsbury.

Sperber, D. (2005). Explicar la cultura. Un enfoque naturalista. Madrid: Morata.

Ungar, S. (2000). Knowledge, ignorance and the popular culture: Climate change versus the ozone hole. Public Understanding of Science, 9, 297312. doi: 10.1088/0963-6625/9/3/306

Ungar, S. (2007). Public scares: Changing the issue culture. In S. C. Moser, \& L. Dilling (Eds.), Creating a climate for change. Communicating climate change and facilitating social change. Cambridge: Cambridge University Press.

This article is part of the Resclima Project, funded by the Ministry of Economy and Competitiveness of the Government of Spain within the VI National R+D Programme 2008-2011, year 2012, REF. EDU2012-33456 (www.resclima.info).

Pablo Ángel Meira Cartea. Professor of Environmental Education at the University of Santiago de Compostela (Spain). He is member of the Social Pedagogy and Environmental Education Research Group and the director of the Resclima research project (www.resclima.info). He has written several books on climate change, education and communication. 